\title{
Solid-state welding of ultrafine grained copper rods
}

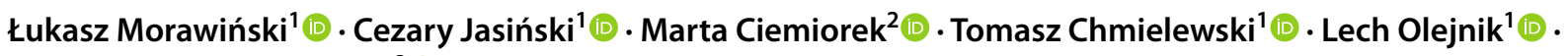 \\ Małgorzata Lewandowska²
}

Received: 25 November 2020 / Revised: 5 May 2021 / Accepted: 6 May 2021 / Published online: 27 May 2021

(C) The Author(s) 2021

\begin{abstract}
The article focuses on the Direct Drive Rotary Friction Welding of ultrafine-grained copper rods, which feature increased mechanical properties and good electrical properties, yet are limited in size. The use of UFG metals is often limited by the too small dimensions of semi-finished elements produced by SPD methods. Therefore, the production of finished machine parts from UFG metals is currently economically unjustified. Dismissal of dimensional limitations can be done by introducing joining to technological processes. The proposed joining method does not lead to a melting of the material in the joining zone or excessive degradation of the UFG microstructure. To obtain the best results, the research used the method of low-energy welding of two kinds of specimens: with a flat or a conical contact surface. In the article, the authors present, by means of metallographic microsections and microhardness measurements, the influence of rotational speed, welding pressure and conical shape contact surface on the quality of the obtained joints. The conducted research made it possible to obtain good quality joints whose microhardness is reduced only by about $10 \%$ in comparison with the base material and the tensile strength dropped from only 397-358 MPa.
\end{abstract}

Keywords Friction welding $\cdot$ DD-RFW $\cdot$ UFG $\cdot$ Copper $\cdot$ ECAP

\section{Introduction}

In recent years, there has been significant interest in the manufacturing of ultrafine-grained (UFG) metals, i.e., those with an average grain size of less than $1 \mu \mathrm{m}$. The main advantage of such metals is their improved mechanical properties that results from a combined effect of strain hardening and an increase in the number of grain boundaries [1]. UFG metals can be fabricated by virtually any metal forming method that imposes extremely large plastic deformations in a substantial material volume. This group of processes is known as Severe Plastic Deformation (SPD), and on such method, Equal Channel Angular Pressing (ECAP), is notable for making it possible to achieve a significant grain refinement due to the fact that the plastic deformation takes place in a

Łukasz Morawiński

lukasz.morawinski@pw.edu.pl

1 Warsaw University of Technology, Faculty of Production Engineering, Narbutta 85, 02-524 Warsaw, Poland

2 Warsaw University of Technology, Faculty of Materials Science and Engineering, Wołoska 141, 02-507 Warsaw, Poland simple shear deformation mode. ECAP proposed by Segal [2] is one of the most commonly used and recognized SPD techniques [3] to produce submicrometer grain sizes [4], especially for barstock [5], and has been extensively studied by many researchers [6]. In [7], a new die design has been proposed for processing of materials using equal channel angular extrusion. Parameters and recommendations for the ECAP process were discussed in [8]. ECAP can be applied for the electronics and aerospace industries [9] and electrical contact wire production [10]. Nonetheless, it is not possible to manufacture long rods using a conventional ECAP process, which limits opportunities for commercialization. A possible alternative would be to develop joining methods through which shorter bars could be put together with no deterioration in their properties. One of the most popular joining methods, welding is believed to be detrimental to UFG materials, because the heat generated causes recrystallization, thereby reversing the process of grain refinement. To avoid such a loss of the enhanced mechanical properties of UFG stock, other joining methods are applied to UFG materials, such as Friction Stir Welding (FSW), Rotary Friction Welding (RFW) [11] or Linear Friction Welding (LFW) [12] during which the melting temperature of the 
base material is not reached, and its unique mechanical properties are, therefore, preserved.

In the literature, there are reports on joining UFG materials using friction welding [13], such as RFW for joining UFG aluminum alloys [14]. For these kinds of reports, tensile test and microhardness are usually carried out [15]. However, the number of these reports is limited. The available tests have shown that a material with a poorly developed UFG structure is highly susceptible to friction welding. Although a significant decrease in the material's hardness was observed in the joint area, its tensile strength significantly exceeded the joint strength of the base material. Other published reports on RFW tests were carried out on 316L UFG steel rods and showed quite a significant deterioration in mechanical properties, where the microhardness in the weld area dropped by $40 \%$ [16]. Other attempts at joining UFG copper were made using FSW [17], where significant grain growth and an associated decrease in hardness in the heat-affected zone were observed.

SPD techniques are extremely effective in enhancing the mechanical strength of pure copper. Processing copper using ECAP results in a significant drop in grain size, from several dozen $\mu \mathrm{m}$ to less than $1 \mu \mathrm{m}$ after 3 passes, whereas after just 4 or 5 passes, depending on the type of copper, the tensile strength and hardness of the material increases from several dozen for 99.95\% [18], 99.98\% [19] and oxygen-free post-ECAP annealed $99.99 \%$, OFCA [20] pure copper up to almost one hundred percent in the case of pure oxygen-free 99.99\% copper, OFC [21]. During processing, after exceeding a specific accumulative strain, the mechanical property values saturate, and further passes only result in fluctuations of the properties by a few percent. After 8 passes, the tensile strength, depending on the type of copper (99.98\% pure [19], commercial purity level $99.90 \%$ [22] and electrolytic tough pitch (ETP) [23]) increases by at least $60 \%$ in comparison with the coarse-grained material. Subsequent operations may cause a slight decrease in the mechanical properties of $90.77 \%$ [24] and $99.44 \%$ [25] UFG pure copper, as further processing no longer causes a noticeable drop in grain size [19]. However, 2-3 min of annealing at a temperature of about $160{ }^{\circ} \mathrm{C}$ causes a decline of several percent in the mechanical properties of the UFG material [21]. Annealing at a temperature above $200{ }^{\circ} \mathrm{C}$ leads to a significant decrease in microhardness in the case of $99.99 \%$ [26], 99.98\% [27] pure copper and electrolytic tough pitch copper [23]. The energy accumulated in the material during SPD processing leads to a faster onset of recrystallization processes. The higher the temperature and the longer its duration, the greater the decrease in the mechanical properties of UFG copper caused by grain recrystallization. Only properly selected friction welding parameters make it possible to obtain a connection that does not feature a large deterioration of mechanical properties in the joint area for a material with a well-developed UFG structure. For 316L steel, the decrease of ultimate tensile strength UTS $=1250 \mathrm{MPa}$ was $29 \%$ [16] or $33 \%$ [28].

Apart from good mechanical properties, UFG copper features excellent electrical conductivity, which, however, is affected by SPD processing. The electrical conductivity of UFG copper after 5 ECAP passes decreases by only $8 \%$ [23] and starts to increase slightly with subsequent passes [25], but never reaches the value of the initial material. In [29], it was proven that short-term annealing at low a temperature after ECAP processing results in relatively high electrical conductivity and while preserving the beneficial mechanical properties. These results indicate that ECAP processing makes it possible to manufacture a high-strength material whose electrical conductivity is only slightly lower than that of the initial, coarse-grained material. A material characterized by such properties constitutes an attractive product for use in electrical applications. The only limiting factor is the necessity of joining small billets into larger objects, which can cause deterioration of the mechanical properties caused by grain recrystallization during friction welding. Therefore, it is necessary to use the lowest possible temperature and joining time so as to reduce the deterioration of the mechanical properties in the joining zone.

The aim of the article is to establish optimal parameters for the friction joining of UFG copper rods using DD-RFW to acquire a joint having the largest possible total coverage degree, and whose mechanical properties are as close as possible to those of the base material.

\section{Direct drive rotary friction welding}

DD-RFW (direct drive friction welding, i.e., with a continuous drive) is a modification of RFW, one of the most popular friction welding $(\mathrm{FW})$ methods, whose common feature is the use of heat generated by friction in a joining area to induce plastic deformation in a controlled manner. The aim of exerting pressure on and mixing the plasticized metal is to obtain a stable connection of the elements in the solid state by creating a metallic bond. In typical RFW, there are two important technological phases: the friction phase and the forging phase, where several technological parameters can be distinguished: rotational speed $n$, pressure in the friction phase $P_{T}$, pressure in the forging phase $P_{S}$, friction time $t_{T}$ and forging time $t_{S}$. Normally in RFW, a shortening $S_{T}$ of the welded rods (burn-off) is inevitable. This is a result parameter, although in some welding machines it is possible to set the value of the initial shortening $S_{T}$. In this research, a DD-RFW welding process was applied, as it offers wide possibilities for setting the process parameters. The heating time and upset distance are pre-set, but forging phase can be controlled by adjusting the braking time, axial force 
and forging time [30]. When determining the values of DDRFW technological parameters, shown in Fig. 1a, both the cross-section diameter $\mathrm{d}$ of the joined rod and the type of material from which it is made must be taken into consideration, since friction torque is dependent on the diameter and maximum allowable friction pressure on the yield strength.

Research on welding new materials requires full control of the process parameters. As already mentioned, DD-RFW has such capabilities, which makes it the most frequently chosen method of rotary friction welding. Parameter control is especially important when welding UFG materials, which are very susceptible to the amount of energy supplied to the weld area. The correct welding of such materials requires a minimal energy supply, which in turn requires precise control over the welding rotational speed and time. The use of DD-RFW makes it possible to conduct research aimed at determining a parameter window that permits the lowest possible deterioration of the properties of the UFG material in the joint area.

There is little information in the literature on RFW lowenergy welding. This is because most conventional materials can be welded at higher temperatures and times, without serious deterioration of their properties, unlike UFG metals, which are particularly sensitive to processing conditions. Moreover, their use is often limited by the restricted dimensions of semi-finished products manufactured with the SPD methods. Welding is crucial for joining single parts in the production of semi-finished elements by obtaining long UFG bars and tubes. Nevertheless, there are only few articles dealing with Rotary Friction Welding of UFG materials. Attempts at welding UFG copper with this method have not been discussed in the literature, which makes this work innovative in this field.

Welding UFG copper seems to be a promising solution for joining rod sections in the future. Only after obtaining sufficient length, it is possible to produce copper elements with high strength and good conductivity in an economically justified manner using multi-position machines (mass) or CNC machines (unit). Long bars made of ultrafine-grained material retain the ability to plastic deformation and can be transformed by metal forming methods into machine parts or semi-finished products with high strength properties used, among others, in the energy or automotive industry (electric cars). The research presented in this article is the first attempt to achieve this goal.

\section{Experimental}

The DD-RFW tests were carried out on an HWH RSM200 machine (Hamburg, Germany) (Fig. 2), where such process parameters as the pressure in the friction phase $\left(P_{T}\right)$ and forging phase $\left(P_{S}\right)$, the duration of the friction phase $\left(t_{T}\right)$ and forging phase $\left(t_{S}\right)$, and the rotational speed $(n)$, were adjusted. The HWH machine is a typical modular friction welding machine equipped with the RSM200 model head. It allows for welding objects with a diameter of up to $12 \mathrm{~mm}$. The basic parameters of the mentioned device are the maximum rotational speed of $23,300 \mathrm{rpm}$, the engine power of $1.8 \mathrm{~kW}$ and the maximum pneumatic pressure of $10.7 \mathrm{kN}$. The pressure in the forging phase $\mathrm{P}_{\mathrm{S}}$ was set at $5.5 \mathrm{bar}$, the friction time $t_{T}$ was $20 \mathrm{~ms}$, and the forging time was $3000 \mathrm{~ms}$. During the tests, two process parameters were changed, i.e., $n$ and $P_{T}$. The rotational speed $\mathrm{n}$ was altered in a range of 13,000-20,000 rpm, and the pressure in the friction phase $P_{T}$ in a range of 2.0-4.5 bar. One of the samples was clamped in the collet of the "ER20" system (CMT type according to DIN 6499), and the other in a pneumatic vice. Both jaws of the vice have a semicircular recess which, when closed, creates a hole of a size matching the diameter of the clamped object.
Fig. 1 Technological characteristics of DD-RFW operation with a flat (a) and a conical (b) contact geometry; specimens with a conical or flat contact surface (c)

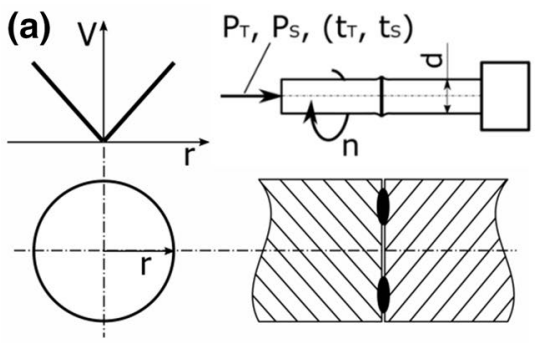

(c)

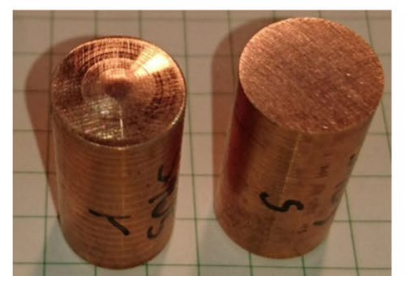

(b)

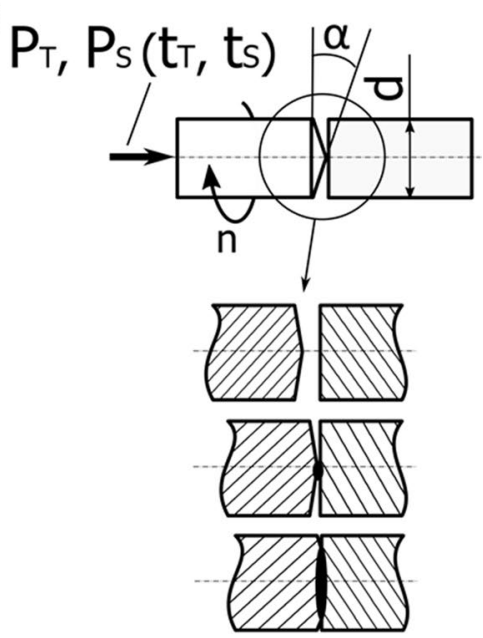


(a)

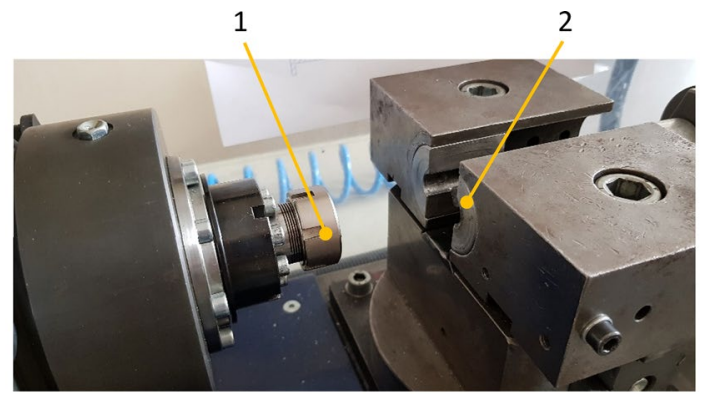

(b)

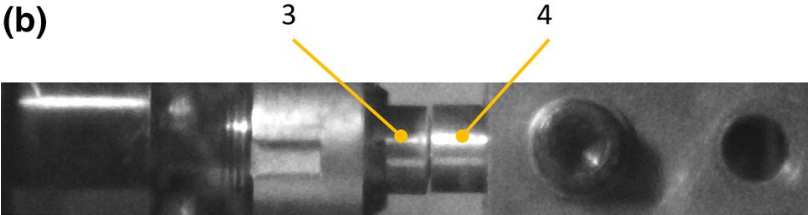

Fig. 2 Working area of the HWH machine (a) and specimens during the welding process recorded by a high-speed camera (b), 1-rotating specimen holder, 2-still specimen holder, 3-rotating specimen (conical surface), 4-still specimen (flat surface)

To compare the welding results for rods with variously shaped contact surface, the welding was carried out on two kinds of specimens having either a flat or a conical contact face (Fig. 1c). The use of a conical surface required the introduction of a new parameter, which was the angle of inclination of the conical surface $\alpha$, as shown in Fig. $1 b$. The introduction of a conical surface meant that, during the welding, friction and temperature were initially generated at the point of contact, i.e., near the sample axis. A properly selected angle ensured a gradual increase in the weld surface from the axis of the rod to its periphery while overheated material was removed outside the rod. The gradual development of the joint with the simultaneous use of extremely short heating times prevented the material from overheating at the weld zone, avoiding a deterioration of the beneficial properties of the UFG metal. A slant angle of $\alpha=8^{\circ}$ was chosen. Based on the experimental research, it was shown that this angle allows its maximum shortening to the base at the maximum used rotational speed of $n=20,000 \mathrm{rpm}$.

The parameters used for the DD-RFW process were selected so as to obtain the widest possible range of results for the two kind of specimens (flat or conical contact geometry). The parameters for the welding trials are presented in Table 1.

The material used for the tests was ultrafine-grained electrolytic tough pitch copper rods with a diameter of $11.5 \mathrm{~mm}$. EBSD maps measured in the transverse and longitudinal planes are shown in Fig. 3. To achieve a UFG microstructure, coarse-grained copper rods were subjected to 6 passes of multi-turn ECAP [31] processing, which resulted in a total strain of 9.2, an average grain size of $0.66 \pm 0.10 \mu \mathrm{m}$ and $0.51 \pm 0.39 \mu \mathrm{m}$, and a high fraction of High Angle Grain Boundaries (HAGBs), equal to $56 \%$ and $59 \%$ for the longitudinal and transverse planes, respectively. The specimens for EBSD examinations were polished using sand paper up to 4000 grit and then electrochemically polished using a perchloric acid-ethanol solution (1:4). Carl Zeiss Axio Scope

Table 1 RFW parameters window for UFG copper

\begin{tabular}{|c|c|c|c|c|c|c|c|c|c|c|c|}
\hline \multicolumn{6}{|c|}{ Specimens with flat contact surface } & \multicolumn{6}{|c|}{ Specimens with conical contact surface } \\
\hline № & $t_{T},[\mathrm{~ms}]$ & $t_{S},[\mathrm{~ms}]$ & $n,[\mathrm{rpm}]$ & $P_{T}$, bar $]$ & $P_{S},[$ bar $]$ & № & $t_{T},[\mathrm{~ms}]$ & $t_{S},[\mathrm{~ms}]$ & $n,[\mathrm{rpm}]$ & $P_{T},[$ bar $]$ & $P_{S},[$ bar $]$ \\
\hline R106 & 20 & 3000 & 13,000 & 4.0 & 5.5 & S105 & 20 & 3000 & 13,000 & 4.5 & 5.5 \\
\hline R501 & 20 & 3000 & 21,000 & 4.0 & 5.5 & S101 & 20 & 3000 & 20,000 & 4.5 & 5.5 \\
\hline R502 & 20 & 3000 & 21,000 & 2.0 & 5.5 & S109 & 20 & 3000 & 13,000 & 2.0 & 5.5 \\
\hline
\end{tabular}
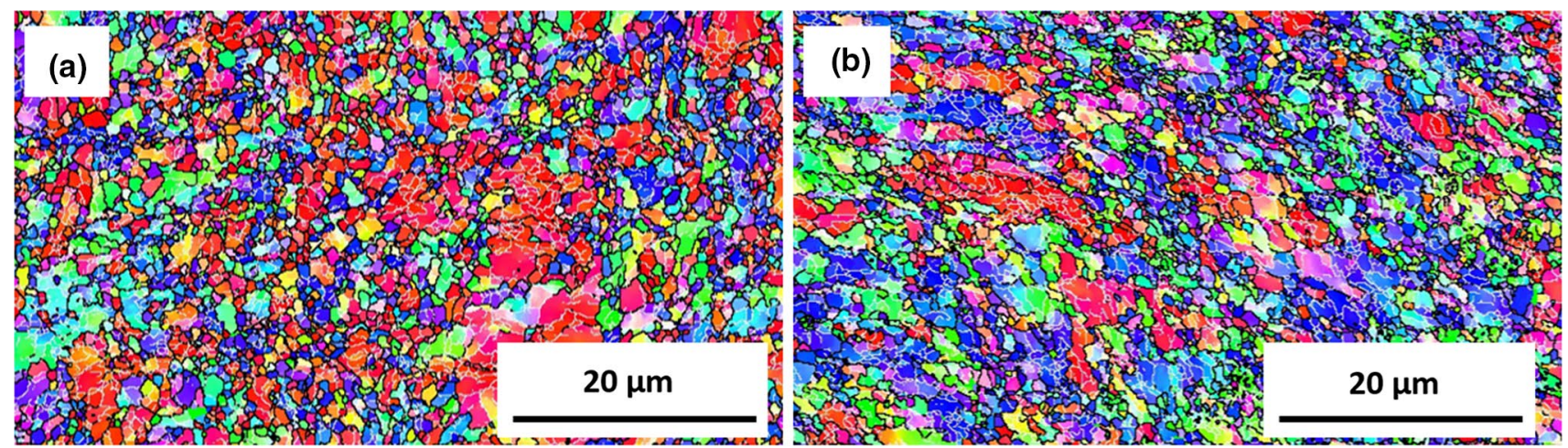

Fig. 3 Colored maps obtained from EBSD analysis of transverse (a) and longitudinal (b) planes of UFG copper used for the RFW 
optical microscope was used for metallographic micrographs, for which specimens were mechanically prepared using sand paper up to 4000 grit, diamond suspension up to $1 \mu \mathrm{m}$ and etched using hydrochloric acid-ferrite chloride ethanol solution.

Just before the friction welding process, the contact surfaces of the specimens were sanded with 400 grit emery paper, degreased, and blown with compressed air to remove the oxide layer.

\section{Results}

\subsection{Specimens with a flat contact surface}

To assess the quality of the obtained joints, Vickers microhardness measurements were made under a load of $200 \mathrm{~g}$, and the microstructure of the joints was examined under an optical microscope. In addition, the total coverage degree (TCD) and joint coverage degree (JCD) were determined from an analysis of the cross-section areas, and expressed as $\% \mathrm{TCD}$ and \% JCD by the following equations:

$\% \mathrm{TCD}=L_{W} / d \times 100$

$\% \mathrm{JCD}=L_{W} / L_{j} \times 100$

where $L_{w}$ is the length of the welded material, $d$ is the specimen diameter, and $L_{j}$ is the distance between the joint edges.

Figure 3a presents a cross-section of the sample R106 with a flat contact surface obtained at $n=13,000 \mathrm{rpm}$ and $P_{T}=4.5$ bar. These parameters resulted in best connection at the bar periphery that constituted only a part of the surface of the face of the sample.

Despite using a wide range of parameters, none of the attempts was fully successful, as it was not possible to produce a joint without discontinuities in the weld, as reflected by the low JCD values of 70\%, 39\% and 50\% for the R106, R501 and R502 samples, respectively, and by the TCD values $(44 \%, 31 \%$ and $45 \%)$. This was attributed to the very short welding time chosen to prevent an excessive temperature increase and an associated degradation of mechanical properties. Due to the short time and low rotation velocity around the specimen axis, the samples could not be joined properly. Increasing the friction time caused the material to overheat around the specimen's circumference. Despite the incomplete connection of the rods, microhardness tests (Fig. 4b) were conducted in the connection area, marked by vertical dashed line in Fig. 4a. These were aimed at assessing whether the parameters used during the welding process significantly degraded the UFG microstructure. The tests showed that the decrease was about $20 \mathrm{HV} 0.2$, which is about $15 \%$. The obtained result indicates a correct selection of process parameters in respect of maintaining the properties of the UFG material; however, these parameters did not lead to a full connection of the flat-face bars.

Due to unsuccessful attempts to connect flat-face rods with $n=13,000 \mathrm{rpm}$, welding tests were carried out at an increased rotational speed and various pressure values. The change in these parameters was aimed at increasing the temperature generated, and consequently, at achieving a connection over the whole area. All attempts to join specimens with a flat contact surface using the given parameters were unsuccessful. Figure 5 shows metallographic micrographs of rods from welding tests R501 (Fig. 5a) and R502 (Fig. 5b).
Fig. 4 Microstructure in axial cross-section of the R106 sample with a flat contact surface (a) and microhardness HV0.2 profile recorded along a selected line parallel to the axis of the joint (b), red rectangle shows the position of EBSD map (a)

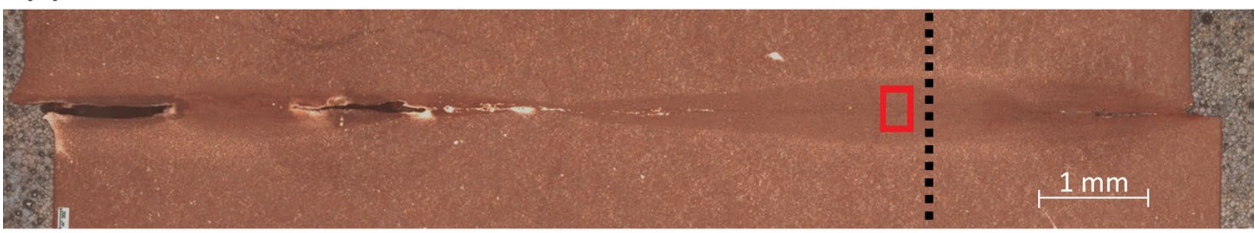

(b)

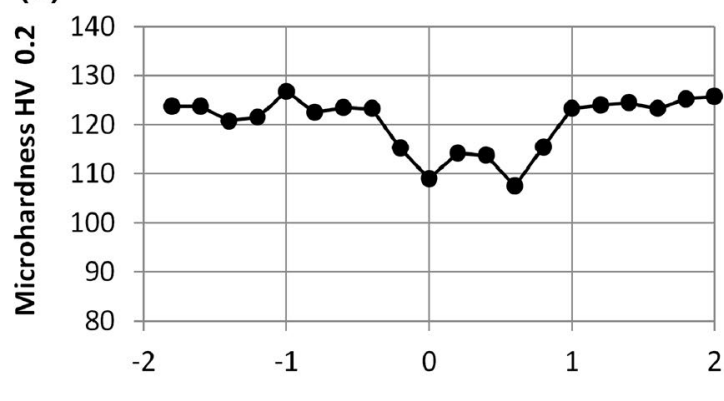

Distance from the center of the joint [mm] 
Fig. 5 Microstructure in axial cross-section with longitudinal hardness measurement of the joints for two specimens with a flat contact surface: a R501, b R502 (a)

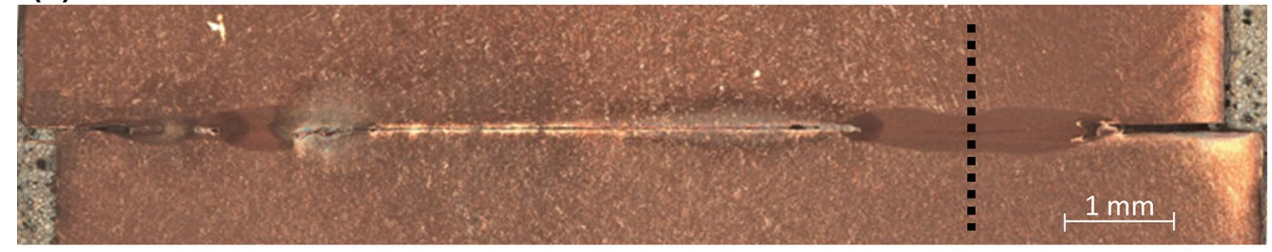

(b)

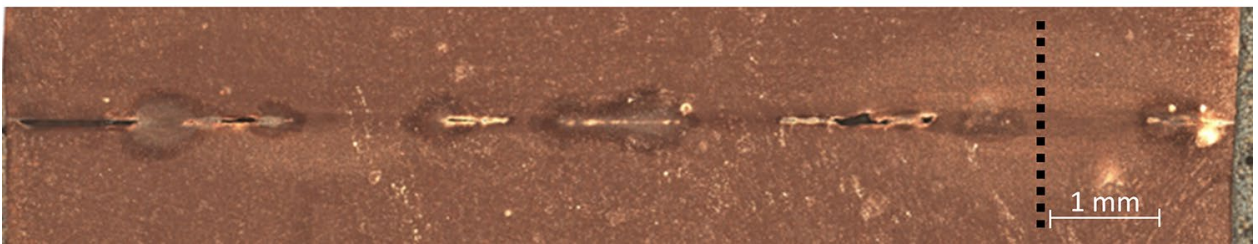

Despite the use of different sets of parameters, numerous discontinuities in the material occurring along the weld can be observed on all of the specimens. The discontinuities are visible in the discoloration caused by the etching fluid flowing from the voids in the joint. The differences in the discontinuity system of the welds can be explained by the longer friction time, which depended on the rotational speed $\mathrm{n}$ and the pressure value $P_{T}$. The final friction time was affected by braking the rotation, which must be especially carefully investigated and taken into account when designing a process using extremely short welding times. Higher rotational speeds cause a longer braking time, as well as a reduction in pressure, which reduces friction due to there being less pressure on the contact surface. Finally, when using very short welding times, the effect of other process parameters on friction time must be taken into account, which ultimately results in discrepancies between the friction time set on the machine and the actual value.

\subsection{Specimens with a conical contact surface}

To acquire better joint quality, specimens with a conical contact face were used, which resulted in acquiring joints without discontinuities in the weld area, as shown in Fig. 6. The use of a conical surface meant that, in the initial phase, the weld formed at the rod axis. During the process, as the cone shortens the weld expands toward the rod periphery, such that the material in the final joint is not overheated, and the first layers of the cone material are pushed outside the joint as a weld flash.
Fig. 6 Microstructure in axial cross-section of the joints for specimens S105 (a), S101 (b) and $\mathrm{S} 109$ (c) with a conical contact surface-dimension for burn-off, red rectangles indicate the position of EBSD maps

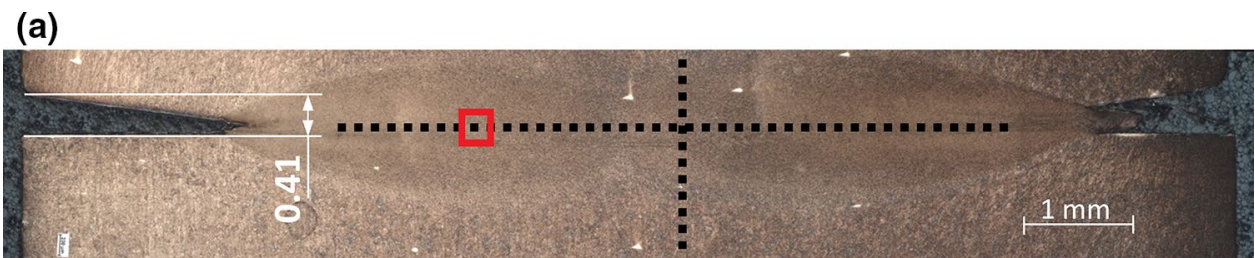

(b)

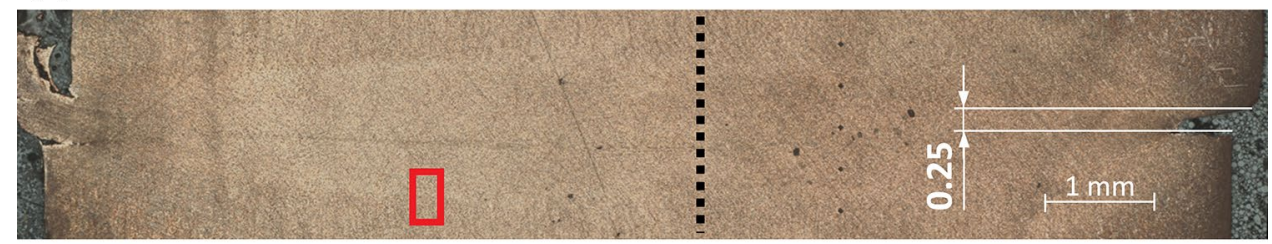

(c)

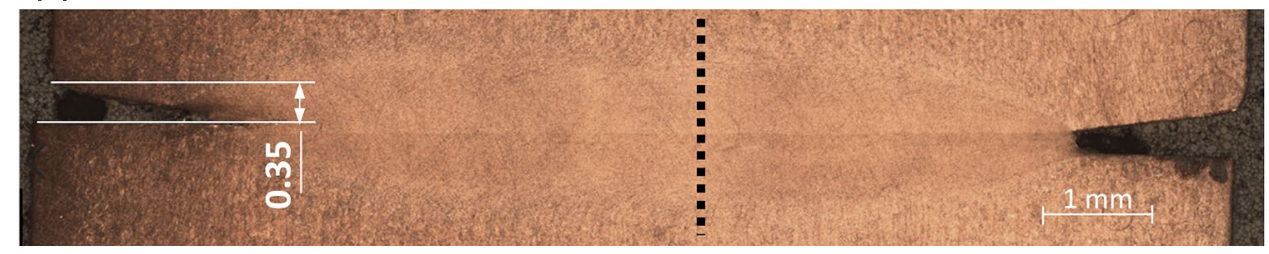


The rotational speed in Fig. 7 makes it possible to precisely determine the moment of contact of the rods, since then its value is clearly reduced due to frictional resistance. The first vertical, dashed line introduced at the point of rotational speed reduction indicates the time value at which the bars came into contact, and the second horizontal line indicates the end of the friction stage after the machine spindle stopped and the rotational speed dropped to $n=0$.

Figure $7 \mathrm{a}$ shows the rotational speed and pressure as a function of time for specimen S105 welded at $n=13,000 \mathrm{rpm}$ and $P_{T}=4.5$ bar. The friction time determined is comparable to Fig. 7b, which shows the process for specimen S101, despite a much higher rotational speed set at the machine control. The graphs show that the real times of friction are much greater than those determined by the machine control. With a set value of $t_{T}=20 \mathrm{~ms}$, the machine needs much more time for deceleration, which extends the friction time to about $200 \mathrm{~ms}$. Figure $7 \mathrm{c}$ shows the course of the welding parameters for specimen S109. During this test the pressure was reduced, which resulted in a visible increase in the friction time to about $270 \mathrm{~ms}$ despite the low rotation speed of $13,000 \mathrm{rpm}$. The real pressure, as well as the friction time, were not identical to the values set at the machine control.
A very short friction phase means that the pressure was not able to reach the set value. Only the use of low pressures can approximately achieve the desired value during the friction process.

The height of the cone before welding was about $0.8 \mathrm{~mm}$, and a dimensional analysis of the microstructure in axial cross-section of the joints, presented in Fig. 6, showed that the shortening of the samples was different in all cases. The greatest shortening was observed for sample welded at a high rotational speed (S101). The least shortening occurred in the sample welded at a lower rotational speed (S105), while an additional pressure reduction at a lower rotational speed resulted in an extension of the friction time, and thus in an increase in shortening (S109).

The TCD was substantially higher than for specimens with a flat contact surface, and was equal to $93 \%, 70 \%$ and 76\% for samples S101, S105 and S106, respectively (Fig. 8). The JCD was equal to $100 \%$ in all cases.

To check the quality of the joints obtained, microhardness measurements were carried out along the specimen axis in the weld area and compared with the value of the initial UFG copper, which was 130 HV0.2. The best result was obtained for the welded specimen S105 with
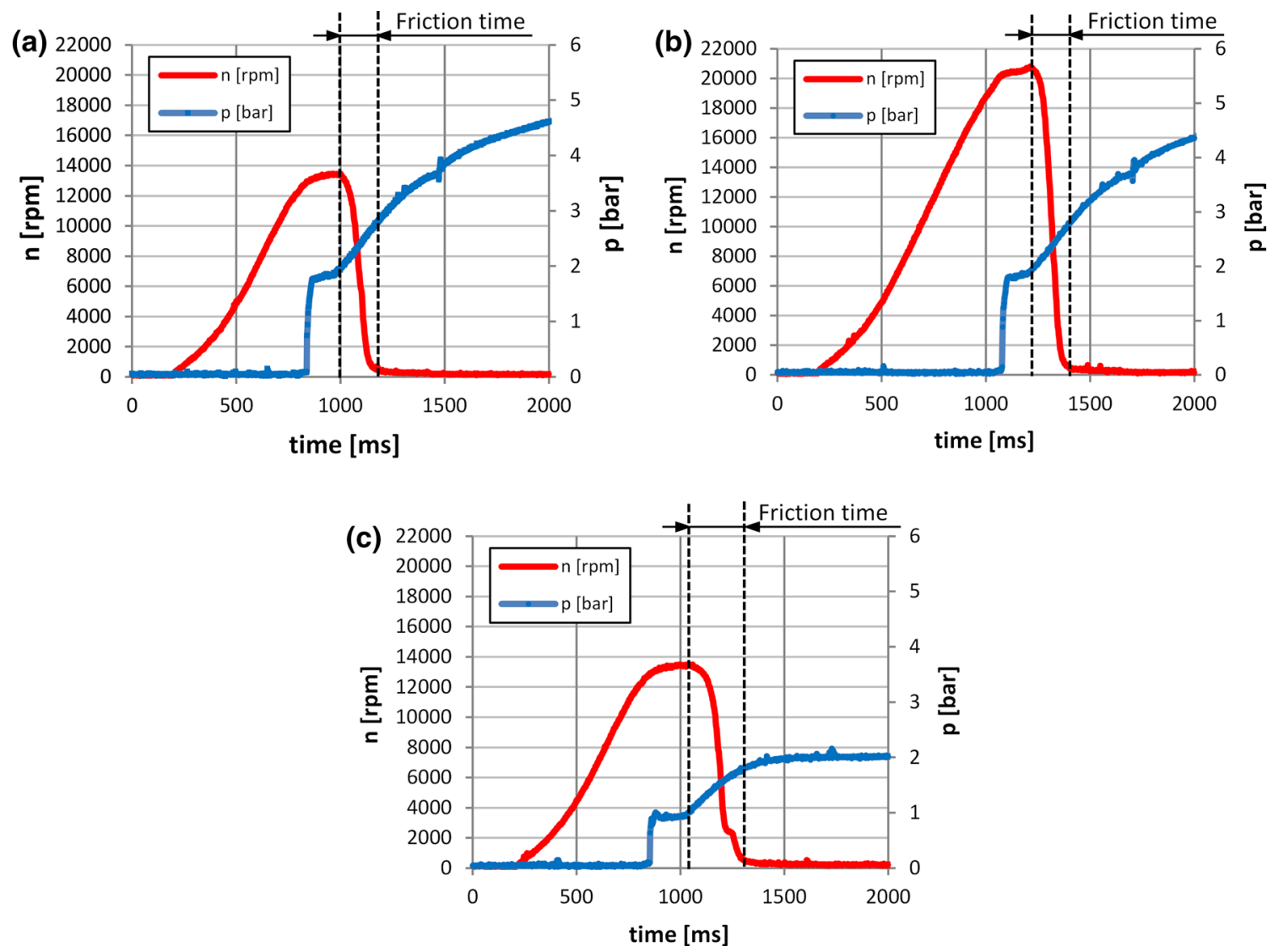

Fig. 7 Rotational speed and pressure as a function of time for trials S105 (a), S101 (b) and S109 (c) 


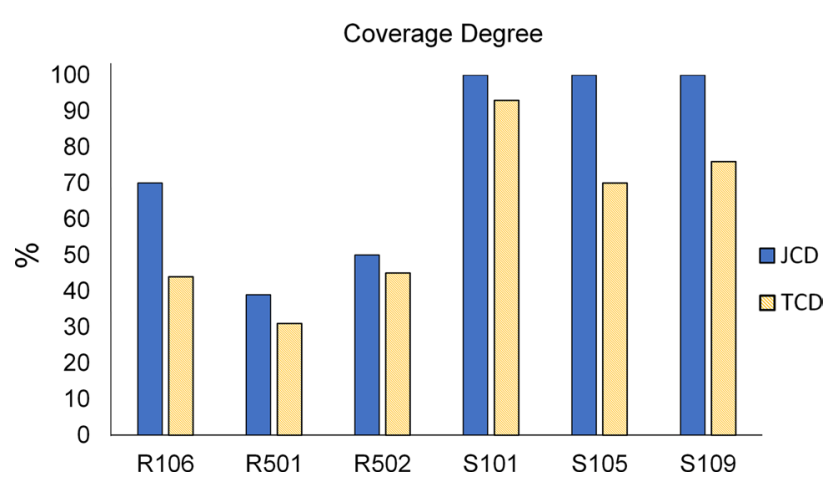

Fig. 8 Coverage degree JCD and TCD for the investigated joints

parameters $n=13,000 \mathrm{rpm}, P_{T}=4.5$ bar, as the hardness drop in the weld area was only $14 \mathrm{HV} 0.2$ in comparison with the base material, or $11.5 \%$ (Fig. 9a), and the tensile strength dropped from only 397 to $358 \mathrm{MPa}$. The most significant deterioration of the properties was obtained for specimen S101 welded at $n=20,000 \mathrm{rpm}$, in which the decrease in hardness was 38\% (Fig. 9b). A comparison of the microhardness diagrams shows that increasing the rotational speed led to a significant degradation of the mechanical properties. The hardness in the joint dropped almost to the level of the coarse-grained material.

The results of the microhardness measurements carried out for the S109 test, in which the same speed was used as in the S105, but a lower pressure, are shown in Fig. 10a. Microhardness measurements showed a 30 HV0.2 decrease in microhardness in the weld area compared with the S105, despite the use of the same rotational speed. The result was, therefore, affected by the low pressure, which increased the deceleration time and caused an increase in the number of rotations during the friction time, consequently decreasing the hardness.

In addition, a microhardness measurement was performed along the weld to check the effect of changing welding time and speed; the results are shown in Fig. 10b. The microhardness along the weld oscillated \pm 5 around the value of $130 \mathrm{HV} 0.2$, and only in the central region of the weld did it drop to a value of 110 HV0.2. These results show that the weld material underwent partial degradation only near the sample axis, where the heat was generated for the longest time, due to the use of a conical surface, which may explain the largest decrease in microhardness.

(b)

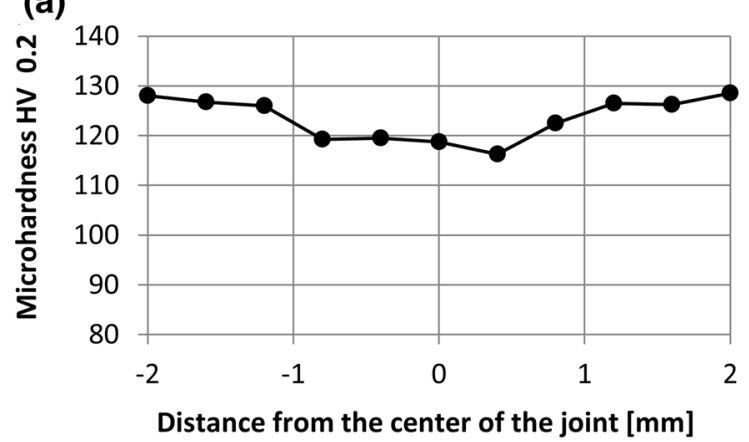

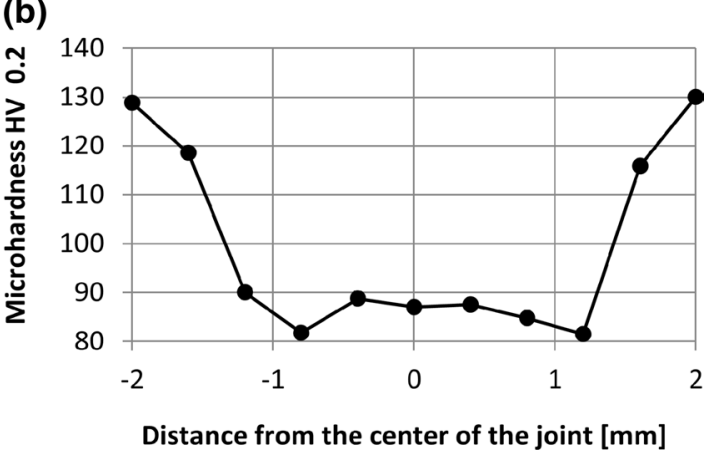

Fig. 9 Microhardness HV0.2 distribution in the cross-section of the weld, recorded along the axis for specimens S105 (a) and S101 (b) (flat to cone surface)

(a)

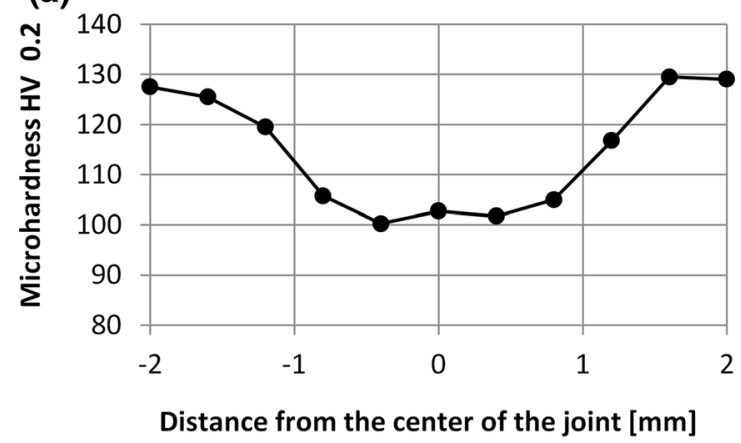

(b)

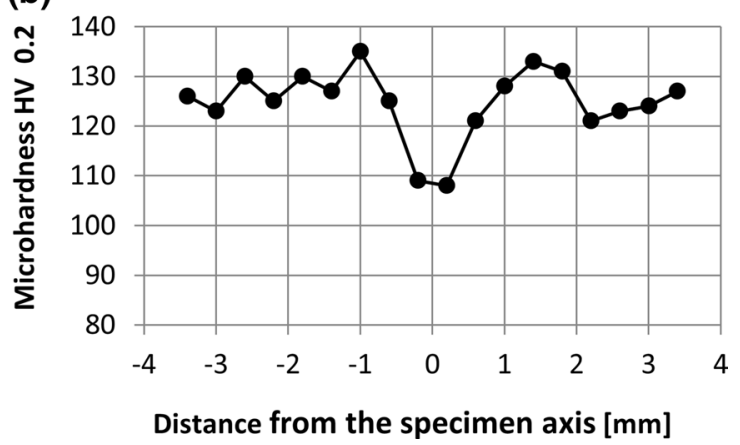

Fig. 10 Microhardness HV0.2 distribution in the cross-section of the weld, recorded along the axis for specimens S109 (a) and along the joint (radial direction) for specimen S105 (b) (flat to cone surface) 


\subsection{Microstructural changes in the weld zone}

Microstructural investigation of the changes in the weld zone was conducted using EBSD technique and Channel 5 software, due to which it was possible to calculate recrystallized fraction of the grains, which are marked by blue color in Figs. 11 and 12. Yellow color indicates substructured grains defined as having misorientation between 1 and $3^{\circ}$. The red color shows grains of misorientation angle $>3^{\circ}$ and is described as 'Deformed' on the column graph. Figure 11 presents the weld zone of the S101 specimen, in which the decrease of the microhardness was the most significant. It is evident that the frequency of the recrystallized, substructured and deformed grains changes with the growing distance from the weld center indicating changes in the microstructure. The fraction of recrystallized grains exceeds $30 \%$ for zone 2 , whereas for zone 1 is lower than $20 \%$. In addition, fractions of grains marked as substructured and deformed also change. In zone 1 , fraction of the deformed grains is twofold larger than in zone 2. As part of the grain boundaries, i.e., Low Angle Grain Boundaries (LAGBs), are thermally and mechanically unstable [32], they can undergo changes under the heat induced by friction welding. Thus, the closer to the weld center, the higher the fraction of grains marked as substructured. This is confirmed by grain size, as in zone $1 d=1.88 \pm 0.75 \mu \mathrm{m}$, whereas in zone $2 d=1.9 \pm 0.81 \mu \mathrm{m}$. Fraction of HAGBs also changes and is equal to 47 and $28 \%$ for the zone 2 and 1, respectively.
Joints characterized by the slightest change of microhardness acquired using conical and flat contact surface are S105 and R106, respectively. In Fig. 11a and c, maps are shown for those joins in the same manner as in Fig. 11, whereas Fig. $12 \mathrm{~b}$ and d shows standard IPF coloring. EBSD mapping was performed in the center of the joints as marked in Figs. 6 and . Joints S105 and R106 present different microstructural features, as in $\mathrm{S} 105$ the grains defined as deformed are dominant, marked by red color, whereas in R106 the substructured, marked by yellow. Well-developed UFG microstructure is evident in Fig. 12d, where close to equiaxed ultra-fine grains with HAGBs marked by black lines are visible. The average grain size acquired in the joint $\mathrm{S} 105$ is $d=0.51 \pm 0.02 \mu \mathrm{m}$ and fraction of HAGBs reaches $51 \%$, whereas for R106 the values are $0.81 \pm 0.42 \mu \mathrm{m}$ and $36 \%$, respectively. This explains the changes of microhardness, which are almost negligible or S105 and more substantial for R106.

\section{Discussion}

\subsection{Influence of processing setup}

UFG copper is prone to recrystallization, and so there is a need to minimize the energy supplied to the joint during welding. This can be guaranteed by extremely short welding times and the lowest possible rotational speed $n$ that
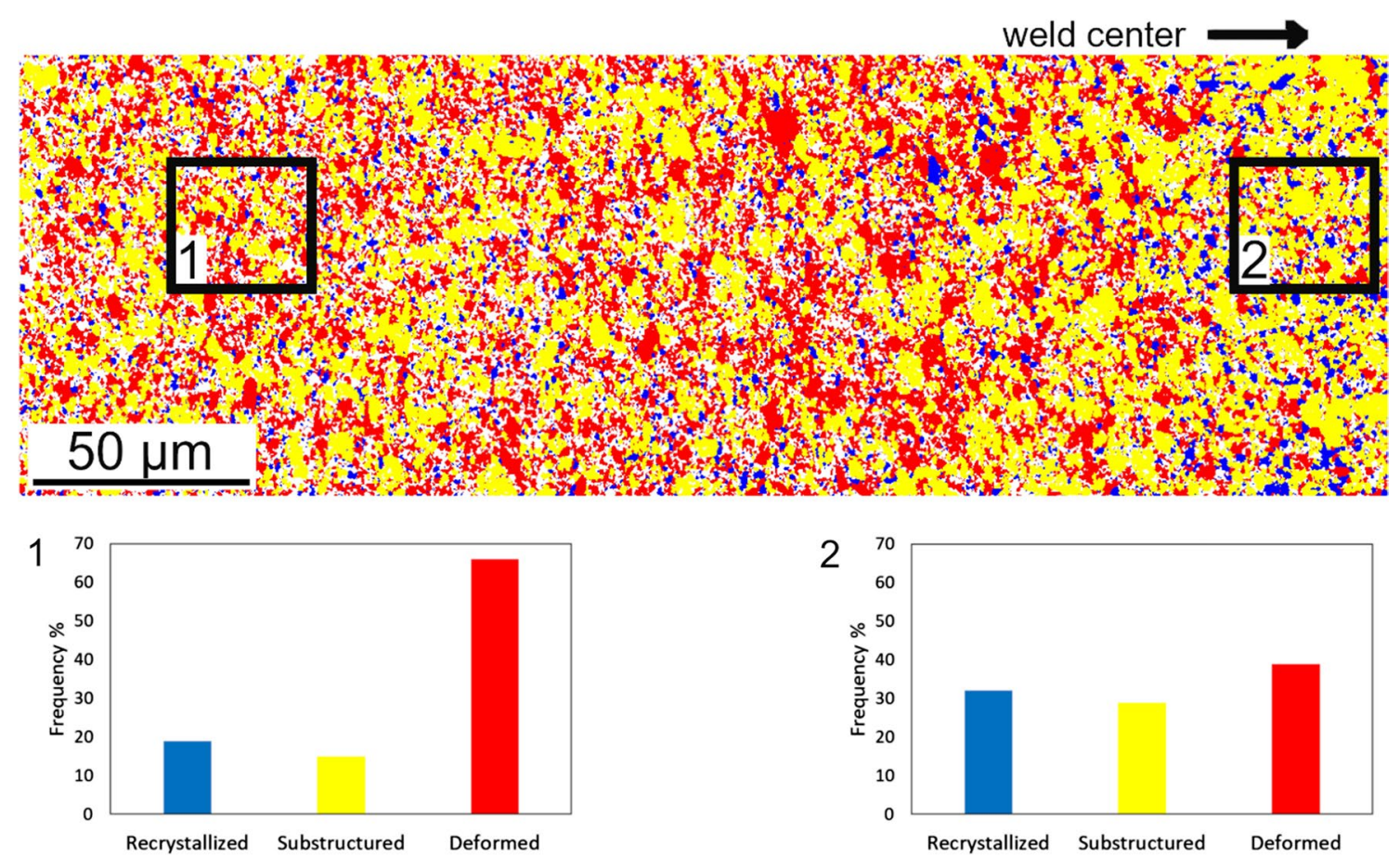

Fig. 11 EBSD map of the weld zone of S101 specimen. The exact position of EBSD maps is marked in Fig. 6 by red rectangle 


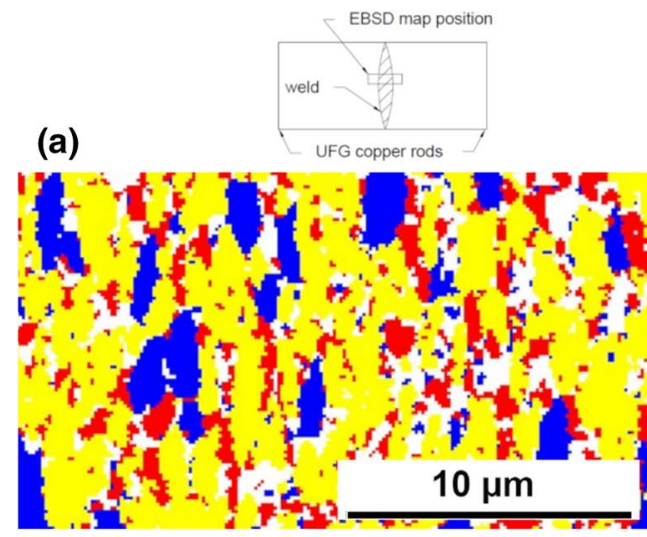

(d)

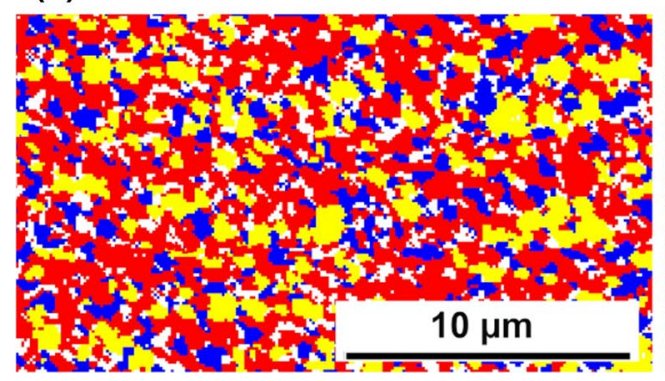

(b)

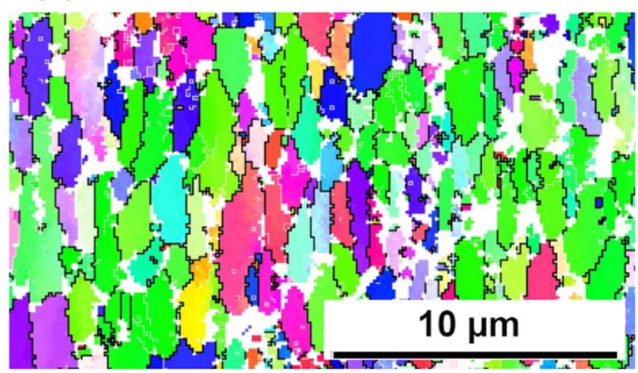

(e)

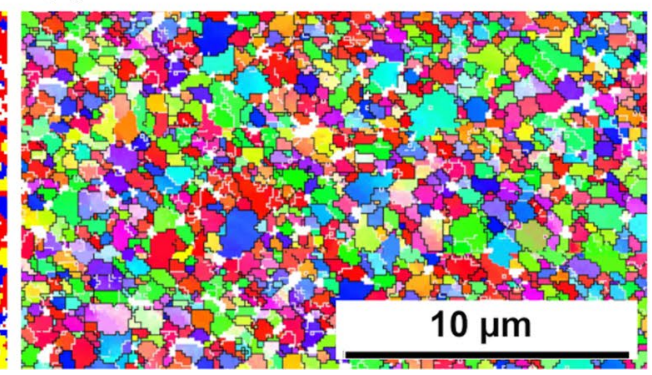

(c)

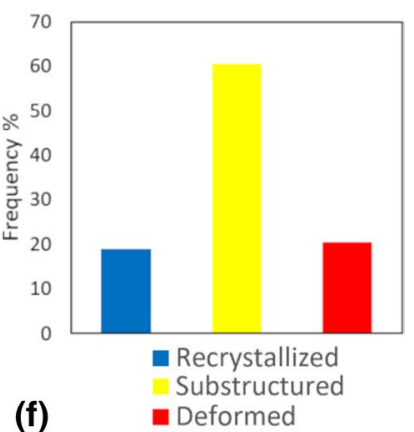

(f)

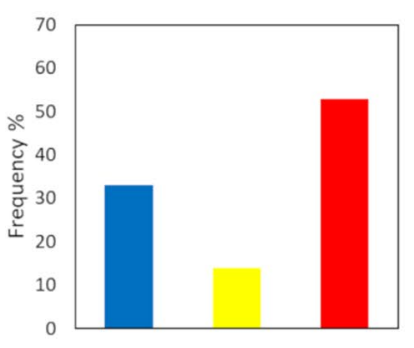

Fig. 12 EBSD maps showing recrystallized fraction (a) and (d) IPF coloring (b, e) and frequency of recrystallized (c, f), substructured and deformed grains of, respectively, joints R106 and S105

will still permit a connection to be made. During the trials conducted on conventional rods with a flat contact surfaces, it was impossible to achieve a proper joint, as the weld was only created close to the periphery of the rod, whereas the area close to the axis remained unconnected (see Fig. 1a). This phenomenon can be explained by the change in linear velocity, which increased together with the distance from the rod axis at a constant rotational speed. At the axis of the rod, the linear velocity equalled zero. Therefore, if the forging time was extremely short, i.e., $20 \mathrm{~ms}$, it was not possible to increase the temperature and plasticize the material to achieve a proper weld. To acquire a good quality joint, it was necessary to generate a high temperature over the whole surface of the rod, starting from the axis and ending on the periphery. Some of the best results were obtained for the conical surfaces, in which a much more even temperature distribution was observed in the joint cross-section than on the flat surfaces [33]. In [34], it was proven that altering the contact surfaces of the joined rods not only improved the connection, but also deteriorated the mechanical properties of the joint to a lesser extent. The influence of contact surfaces geometry is as visible in RFW as the influence of tool design in FSW [35]. Such a beneficial effect joint quality was also observed in this study, as the TCD and JCD were much higher for the samples with a conical contact geometry than for those with a flat contact surfaces.
The tests carried out on the specimens with a conical contact surface showed the lowest decrease in the UFG copper microhardness after the welding of sample S105. For this sample, the rotational speed $\mathrm{n}$ was $13,000 \mathrm{rpm}$. The greatest decrease in microhardness was observed for sample S101, which was welded at a speed of 20,000 rpm. The above comparison shows that rotational speed $\mathrm{n}$ has a significant impact on the properties of the UFG material in the joint area. Additionally, the impact of pressure on the resulting joint was also tested. Specimen S109 was welded at the same speed as $\mathrm{S} 105$, but at a lower pressure. A microhardness test in the area of the joint showed that the resulting hardness was between the results of specimens S105 and S101. To explain the above relationship, the number of rotations made by the specimens during friction was calculated on the basis of the changes in rotational speed recorded by the machine. The rotations were counted from the moment of intra-specimen contact until the machine spindle stopped. The result showed that the lowest number of rotations (25.8) was assigned to the specimen with the best joint parameters (S105). Increasing the speed up to $20,000 \mathrm{rpm}$ in the S101 trial increased the number of rotations to 37.3. As expected, the specimen with intermediate joint properties (S109) made more rotations (34.4) than specimen S105. In this test, the lower pressure reduced the friction torque, and consequently increased the friction time. In conclusion, there is a clear relationship 
between the number of rotations and the decrease in microhardness in the joint area. Increasing the number of rotations performed during friction reduces the microhardness in the joint area. The tests conducted showed that, for short friction times, both the real friction time and the number of rotations performed by the specimens are the result values, and depend mainly on the rotational speed and pressure set.

During friction welding, the heat is generated in the stir zone and adjacent material inducing certain microstructural changes. The processes taking place in the material are usually attributed to dynamic recrystallization and recovery [36]. The latter phenomenon is also considered to be responsible for softening of the material in the weld zone, as due to relatively high stacking fault energy of the copper it is likely to occur. Moreover, due to recrystallization, the grain coarsening is observed, which lowers mechanical properties. Such softening of the materials was observed in all the welds investigated, yet depending on the processing conditions and geometry of contact surface, to various extent. In terms of preserving high mechanical properties, shorter friction time and lower number of rotations is beneficial, as joint S105 and R106 are characterized by significantly smaller decrease of microhardness than others. Those processing parameters proved to be also of utmost importance for sustaining UFG microstructure. The S105 specimen weld zone, exposed to lower number of rotations, is characterized by equiaxed ultrafine grains with high fraction of HAGBs, whereas of S101 specimen the grain size increases without significant reducing of HAGBs, which indicates that due to heat activated processes dislocations creating LAGBs are annihilated. Similar microstructure was observed in other studies and was attributed to the continuous dynamic recrystallization and recovery, caused by the heat supplied during welding [37].

\subsection{Comparison with other studies}

In Fig. 13, the percentage of microhardness reduction is shown for FSW processes carried out on pure coarse-grained or UFG copper. In every study presented, the values that result are strongly dependent on the processing conditions, which have a decisive influence on the properties of the joints obtained, which is also visible in this study. The higher the energy input during welding, the more significant the microhardness change. In the present study, a high rotational speed $n$ lead to a drop in the microhardness of UFG copper in the joint area to a value approaching that of the conventional, coarse-grained material. Decreasing rotational speed resulted in an increased microhardness of the joint.

The lowest decrease in microhardness obtained in the present study, as well as in those cited, was about $10 \%$. These results indicate that DD-RFW is an attractive method for joining rods, since it makes it possible to obtain results

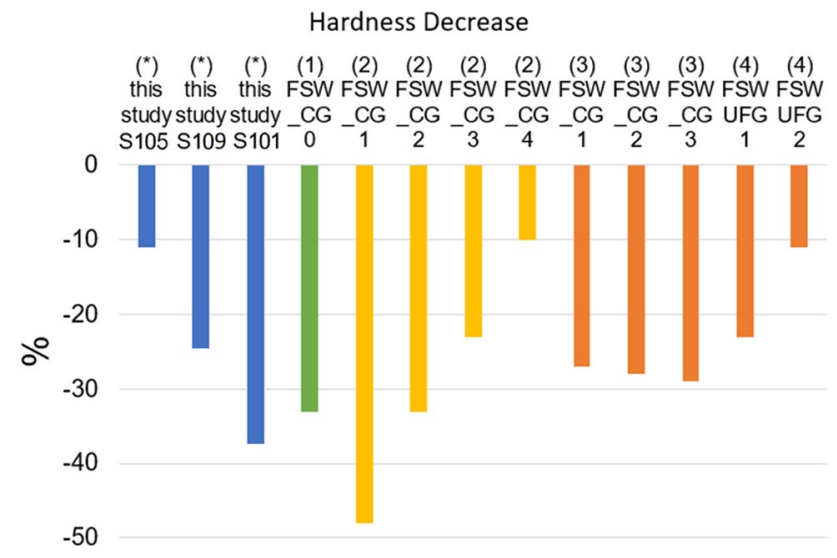

Fig. 13 Decrease in hardness in the stir zone in comparison with the base material (1): [38], (2): [39], (3): [40], (4): [41]

similar to those from FSW, currently considered to be one of the most promising methods.

\section{Conclusions}

The results obtained indicate the great potential of the RFW method in UFG copper welding, since they prove that, using DD-RFW, it is possible to produce joints without a significant deterioration in the mechanical properties of the material. Using extremely short welding times, it is possible to acquire continuous joints with a hardness loss of about $10 \%$. Based on our research, the following conclusions on achieving good quality joints can be formulated:

- The classic strategy for friction welding needs to be changed when a UFG metal is welded on a conventional DD-RFW machine

- Due to the extreme parameters of the welding process, the use of UFG copper rods with a flat contact faces prevents (limits) their full connection.

- To properly connect such rods, conical contact surface should be used. For such specimens, microhardness measurements taken along the joint indicate that it deteriorates only near the axis of the sample, the region affected by heat for the longest time.

- Changing the initial contact geometry to a cone with slant angle of $8^{\circ}$ enabled a comparison to be made between the impact of rotational speed on the shortening of the cone and the changes that resulted in the properties of the UFG material.

Author contributions Not applicable. 
Funding The research leading to these results received funding from the National Science Centre, Poland under the OPUS-14 Grant Agreement No UMO-2017/27/B/ST8/00349.

Availability of data and material Not applicable.

Code availability Not applicable.

\section{Declarations}

Conflict of interest Not applicable.

Open Access This article is licensed under a Creative Commons Attribution 4.0 International License, which permits use, sharing, adaptation, distribution and reproduction in any medium or format, as long as you give appropriate credit to the original author(s) and the source, provide a link to the Creative Commons licence, and indicate if changes were made. The images or other third party material in this article are included in the article's Creative Commons licence, unless indicated otherwise in a credit line to the material. If material is not included in the article's Creative Commons licence and your intended use is not permitted by statutory regulation or exceeds the permitted use, you will need to obtain permission directly from the copyright holder. To view a copy of this licence, visit http://creativecommons.org/licenses/by/4.0/.

\section{References}

1. Valiev RZ, Estrin Y, Horita Z, Langdon TG, Zehetbauer MJ, Zhu YT. Fundamentals of superior properties in bulk nanoSPD materials. Mater Res Lett. 2016. https://doi.org/10.1080/21663831.2015. 1060543.

2. Segal VM. The method of material preparation for subsequent working. Patent no. 575892. USSR. 1977.

3. Langdon TG. The impact of bulk nanostructured materials in modern research. Rev Adv Mater Sci. 2010;25:11-5.

4. Segal VM, Reznikov VI, Drobyshevskiy AE, Kopylov VI. Plastic working of metals by simple shear. Russ Metall. 1981;1:99-105.

5. Rosochowski A. Severe plastic deformation technology. Dunbeath: Whittles Publishing; 2017.

6. Valiev RZ, Estrin Y, Horita Z, Langdon TG, Zehetbauer MJ, Zhu Y. Producing bulk ultrafine-grained materials by severe plastic deformation. J Miner Met Mater Soc. 2006. https://doi.org/10. 1007/s11837-006-0213-7.

7. Mathieu JP, Suwas S, Eberhardt A, Toth LS, Moll P. A new design for equal channel angular extrusion. J Mater Process Technol. 2006. https://doi.org/10.1016/j.jmatprotec.2005.11.007.

8. de Filho AM, Prados EF, Valio GT, Rubert JB, Sordi VL, Ferrante M. Severe plastic deformation by equal channel angular pressing: Product quality and operational details. Mater Res. 2011. https:// doi.org/10.1590/S1516-14392011005000045.

9. Ferrasse S, Segal VM, Alford F, Kardocus J, Strothers S. Scale up and application of equal-channel angular extrusion for the electronics and aerospace industries. Mater Sci Eng A. 2008. https:// doi.org/10.1016/j.msea.2007.04.133.

10. Ma A, Zhu C, Chen J, Jiang J, Song D, Ni S, He Q. Grain refinement and high-performance of equal-channel angular pressed $\mathrm{Cu}-\mathrm{Mg}$ alloy for electrical contact wire. Metals (Basel). 2014. https://doi.org/10.3390/met4040586.

11. Ambroziak A, Korzeniowski M, Kustroń P, Winnicki M. Friction welding of niobium and tungsten pseudoalloy joints. Int J Refract Met H. 2011. https://doi.org/10.1016/j.ijrmhm.2011.02.010.
12. Orłowska M, Olejnik L, Campanella D, Buffa G, Morawiński Ł, Fratini L, Lewandowska M. Application of linear friction welding for joining ultrafine grained aluminium. J Manuf Process. 2020. https://doi.org/10.1016/j.jmapro.2020.05.012.

13. Morawiński $€$, Chmielewski T, Olejnik L, Buffa G, Campanella D, Fratini L. Welding abilities of UFG metals. AIP Conf Proc. 2018. https://doi.org/10.1063/1.5034885.

14. Sahin M, Balasubramanian N, Misirli C, Erol Akata H, Can $\mathrm{Y}$, Ozel K. On properties at interfaces of friction welded nearnanostructured Al 5083 alloys. Int J Adv Manuf Technol. 2012;61:935-43. https://doi.org/10.1007/s00170-011-3775-7.

15. Sahin M, Erol Akata H, Ozel K. An experimental study on joining of severe plastic deformed aluminium materials with friction welding method. Mater Design. 2008. https://doi.org/10.1016/j. matdes.2006.11.004.

16. Skowrońska B, Chmielewski T, Pachla W, Kulczyk M, Skiba J, Presz W. Friction weldability of UFG $316 \mathrm{~L}$ stainless steel. Arch Metall Mater. 2019. https://doi.org/10.24425/amm.2019. 129494.

17. Salahi S, Yapici GG. Fatigue behavior of friction stir welded joints of pure copper with ultra-fine grains, 5th International Biennial Conference on Ultrafine Grained and Nanostructured Materials, UFGNSM15. Proced Mater Sci. 2015. https://doi. org/10.1016/j.mspro.2015.11.097.

18. Smirnov I, Konstantinov A. Influence of ultrafine-grained structure produced by equal-channel angular pressing on the dynamic response of pure copper. Proced Struct Integr. 2018. https://doi. org/10.1016/j.prostr.2018.12.280.

19. Lugo N, Llorca-Isern N, Sunol JJ, Cabrera JM. Thermal stability of ultrafine grains size of pure copper obtained by equal-channel angular pressing. J Mater Sci. 2010. https://doi.org/10.1007/ s10853-009-4139-7.

20. Goto M, Teshima N, Han SZ, Euh K, Yakushiji T, Kim SS, Lee J. High-cycle fatigue strength and small-crack growth behavior of ultrafine-grained copper with post-ECAP annealing. Eng Fract Mech. 2013. https://doi.org/10.1016/j.engfracmech.2013. 07.018.

21. Goto M, Han SZ, Yakushiji T, Kim SS, Lim CY. Fatigue strength and formation behavior of surface damage in ultrafine grained copper with different non-equilibrium microstructures. Int $\mathrm{J}$ Fatigue. 2008. https://doi.org/10.1016/j.ijfatigue.2007.11.001.

22. Collini LL. Fatigue crack growth resistance of ECAPed ultrafinegrained copper. Eng Fract Mech. 2010. https://doi.org/10.1016/j. engfracmech.2010.02.011.

23. Lipinńska M, Olejnik L, Lewandowska M. The influence of an ECAP-based deformation process on the microstructure and properties of electrolytic tough pitch copper. J Mater Sci. 2018. https:// doi.org/10.1007/s10853-017-1814-y.

24. Sanusi KO, Afolabi AS, Muzenda E. Microstructure and mechanical properties of ultra-fine grained copper processed by equal channel angular pressing technique. In: Proceedings of the World Congress on Engineering and Computer Science. 2014; Vol II WCECS 2014, 22-24 October, 2014, San Francisco, USA.

25. Afsari A, Ranaei MA. Equal channel angular pressing to produce ultrafine pure copper with excellent electrical and mechanical properties. Int J Nanosci Nanotechnol. 2014;10(4):215-22.

26. Tao S, Yu-long L, Kui X, Feng Z, Ke-shi Z, Yuan-yong L. The effect of temperature on mechanical behavior of ultrafine-grained copper by equal channel angular pressing. Mater Sci Eng A. 2010. https://doi.org/10.1016/j.msea.2010.05.046.

27. Jiang Q, Li X. Effect of pre-annealing treatment on the compressive deformation and damage behavior of ultrafine-grained copper. Mater Sci Eng A. 2012. https://doi.org/10.1016/j.msea.2012.03. 024. 
28 Skowrońska B, Siwek P, Chmielewski T, Golański D. Friction welding of ultrafine grained 316L steel. Weld Technol Rev. 2018. https://doi.org/10.26628/ps.v90i5.917.

29. Ciemiorek M, Pawliszak Ł, Chromiński W, Olejnik L, Lewandowska M. Enhancing the electrical conductivity of electrolytic tough pitch copper rods processed by incremental equal channel angular pressing. Metall Mater Trans A. 2020. https://doi.org/10. 1007/s11661-020-05818-w.

30. Maalekian M. Friction welding-critical assessment of literature. Sci Technol Weld Join. 2007. https://doi.org/10.1179/17432 9307X249333.

31. Rosochowski A, Olejnik L. Numerical and physical modelling of plastic deformation in 2-turn equal channel angular extrusion. J Mater Process Technol. 2002. https://doi.org/10.1016/S09240136(02)00339-4.

32. Vinogradov A. Mechanical properties of ultra fine-grained metals: new challenges and perspectives. Adv Eng Mater. 2015. https:// doi.org/10.1002/adem.201500177.

33. Alves EP, Toledo RC, Piorino Neto F, Botter FG, An CY. Experimental thermal analysis in rotary friction welding of dissimilar materials. J Aerosp Technol Manag. 2019. https://doi.org/10.5028/ jatm.v11.1068.

34. Pinheiro MA, Bracarense AQ. Influence of initial contact geometry on mechanical properties in friction welding of dissimilar materials aluminum 6351 T6 and SAE 1020 steel. Adv Mater Sci Eng. 2019. https://doi.org/10.1155/2019/1759484.

35. Venkateswarlu D, Mandal NR, Mahapatra MM, Harsh SP. Tool design effects for FSW of AA7039. Weld J. 2013;92(2):41-7.

36. Kobayashi C, Sakai T, Belyakov A, Miura H. Ultrafine grain development in copper during multidirectional forging at $195 \mathrm{~K}$.
Philos Mag Lett. 2007. https://doi.org/10.1080/095008307015660 16.

37. Xua N, Song Q, Bao Y, Jiang Y, Shen J. Achieving good strengthductility synergy of friction stir welded $\mathrm{Cu}$ joint by using large load with extremely low welding speed and rotation rate. Mater Sci Eng A. 2017. https://doi.org/10.1016/j.msea.2017.01.052.

38. Xu N, Song Q, Bao Y, Jiang Y, Shen J. Achieving good strengthductility synergy of friction stir welded $\mathrm{Cu}$ joint by using large load with extremely low welding speed and rotation rate. Mater Sci Eng A. 2017. https://doi.org/10.1016/j.msea.2017.01.052.

39. Xue P, Xiao BL, Zhang Q, Ma ZY. Achieving friction stir welded pure copper joints with nearly equal strength to the parent metal via additional rapid cooling. Scr Mater. 2011. https://doi.org/10. 1016/j.scriptamat.2011.02.019.

40. Khodaverdizadeh H, Mahmoudi A, Heidarzadeh A, Nazari E. Effect of friction stir welding (FSW) parameters on strain hardening behavior of pure copper joints. Mater Des. 2012. https://doi. org/10.1016/j.matdes.2011.09.058.

41. Xie GM, Ma ZY, Geng L. Development of a fine-grained microstructure and the properties of a nugget zone in friction stir welded pure copper. Scr Mater. 2007. https://doi.org/10.1016/j.scriptamat. 2007.03.048.

Publisher's Note Springer Nature remains neutral with regard to jurisdictional claims in published maps and institutional affiliations. 